\section{Perfil epidemiológico do sarampo no Estado de Santa Catarina, Brasil, de 1996 a 2000}

\author{
Measles epidemiology in the State \\ of Santa Catarina, Brazil, 1996-2000
}

Maria Cristina de Sousa Santos Faversani 1

Emil Kupek ${ }^{1}$

Maria Helena Bittencourt Westrupp ${ }^{1}$

\title{
Introdução
}

1 Centro de Ciências da Saúde, Universidade Federal de Santa Catarina,

Florianópolis, Brasil.

Correspondência M. C. S. S. Faversani Departamento de Saúde Pública, Centro de Ciências da Saúde, Universidade Federal de Santa Catarina. Campus Universitário, Trindade, Florianópolis, SC 88040-900, Brasil.

\begin{abstract}
This ecological study, based on an analysis of secondary data from epidemiological surveillance and using the municipality (county) as the unit of analysis, showed that measles vaccine coverage was lower than necessary for eradication (95\%) and control (90\%) in many municipalities in the State of Santa Catarina, Brazil, both before and during the last epidemic in 1997, particularly regarding the second dose of the vaccine, applied as a component of the MMR vaccine, scheduled at 15 months of age. Low vaccine coverage was associated with higher measles incidence. However, during the 1997 epidemic small-scale measles outbreaks were recorded even in municipalities with first-dose coverage of $95 \%$ or higher, particularly among those which also had low second-dose coverage for MMR. Approximately 80\% of all measles cases during 1996-2000 occurred among schoolchildren and young adults. Measles virus circulation in the municipality in the previous year and population density increased the risk of measles. Two imported cases of measles in Santa Catarina in 2004 illustrate that it would be premature to describe the current situation as one of eradication.
\end{abstract}

Measles; Incidence; Measles Vaccine
Este trabalho tem como objetivo examinar a relação entre a incidência do sarampo com cobertura vacinal, densidade populacional e circulação do vírus do sarampo no ano anterior, no período de 1996-2000 que precedeu a eliminação do sarampo no Estado de Santa Catarina. O artigo começa resumindo a evolução epidemiológica do sarampo no Brasil e no Estado, junto com alguns fatores de risco associados, seguindo com medidas de controle da doença.

As primeiras epidemias documentadas no Brasil ocorreram isoladamente, como em 1954 em uma comunidade indígena do Alto Xingu 1. Em 1979, o Brasil apresentou 3.386 óbitos com mortalidade de 3,61 para 100 mil habitantes, subindo para 129.942 casos, ou seja, 97,7 por 100 mil habitantes em 19862 2. A década de 1990 foi o marco inicial no controle do sarampo no Brasil, sendo criado o Plano de Erradicação do Sarampo. Os países das Américas estabeleceram como meta a redução da morbidade e mortalidade por sarampo a partir de 1994, tendo como objetivo principal eliminar o sarampo da região até 2000 3. A falta de manutenção de alta cobertura de vacina contra sarampo (acima de 95\%) em todos os municípios brasileiros possibilitou novos surtos em 1997. O mesmo ocorreu em outros países como Argentina, Bolívia, Colômbia, República Dominicana e Paraguai. 
Os surtos no Brasil tiveram início em São Paulo, capital, com exportação de casos para o Ceará e Bahia, e posteriormente para todas as regiões, inclusive o Estado de Santa Catarina 2. No ano de 1998, o vírus do sarampo continuou circulando principalmente nas regiões Sul e Sudeste. Os estados que mais notificaram casos confirmados foram Paraná (804), São Paulo (403), Amazonas (258), Pernambuco (166) e Distrito Federal (144) 2. Nos anos seguintes, a incidência de sarampo diminuiu significativamente no território nacional, chegando à ausência de casos confirmados por mais de três anos em alguns estados, tais como Santa Catarina 4.

A exemplo do que ocorreu no Brasil, o sarampo no Estado de Santa Catarina representou um sério problema de saúde pública. Em 1991, foi registrado um surto de sarampo quando ocorreram 1.477 casos e a incidência de 30,8 por 100 mil habitantes 5. Em 1995, foram notificados 238 casos em 260 municípios do estado com incidência de 0,79 para 100 mil habitantes. O impacto foi maior entre a faixa etária de 6 meses até 14 anos de idade 4 . A última epidemia no estado ocorreu em 1997, diminuindo gradativamente nos anos seguintes. A partir do ano de 2000, nenhum caso autóctone de sarampo foi confirmado 4.

Desde a sua implantação em 1973, o PNI (Plano Nacional de Imunizações) objetivava uma cobertura mínima de sarampo de $80 \%$ para as áreas urbanas, atingindo crianças de até 5 anos de idade 6 . O esquema de vacina do sarampo era de uma dose aos 6 meses de idade. A partir da década de 1980, foi adotado, em alguns estados, o esquema vacinal de rotina com duas doses, sendo a primeira aos seis meses e a segunda aos doze meses. Entre 1992 e 2000, foi introduzida, em todo o território nacional, a vacina tríplice viral (sigla MMR em inglês) contra os vírus do sarampo, da caxumba e da rubéola. Em função das baixas incidências nos últimos anos e do aumento da imunogenicidade com idade, o esquema vacinal de rotina mudou para uma única dose aos 12 meses de idade em 20037.

Em 1986, Santa Catarina alcançou uma cobertura da vacina contra o sarampo de $79,1 \% 5$, subindo para $95 \%$ ou mais nos anos de 1984 , 1987, 1990, 1992 e 1995 8. Porém, a falta de homogeneidade nas coberturas para todos os municípios do estado e a falta de controle da rede de frio contribuíram para novos surtos (três ou mais casos associados epidemiologicamente num Estado, município, bairro ou área no período de 30 dias) em 1997 e 19985.

Para atingir a meta, a eliminação do sarampo até 2000, foi lançada, em 1992 em nível na- cional, a primeira campanha nacional tipo catch$u p$, tendo como alvo vacinar todas as crianças entre 9 meses e 14 anos. Foram vacinadas mais de 48 milhões de crianças, atingindo uma cobertura de $96 \%$. Os casos de sarampo passaram de 42.532 em 1991 para 2.396 em 1993 9. Em 1995 , foi adotada a segunda medida com a campanha nacional de seguimento (tipo followup), vacinando crianças menores de 5 anos de idade, alcançando cobertura de $77 \%$ 10. Em Santa Catarina, foram vacinadas crianças de um a três anos de idade.

Em resposta ao surto de 1997, houve intensificação de vacinação de rotina nos Estados da federação (primeira dose aos nove meses com vacina monovalente e reforço com tríplice viral aos 15 meses). Também foram efetivadas as campanhas de vacinação em massa, inclusive em Santa Catarina, junto com intensificação de notificação e investigação da doença. Após 1997, passaram a ser vacinados os contatos com casos suspeitos de sarampo que não haviam sido vacinados anteriormente, além da vacinação nas escolas das crianças com 11 anos de idade que não receberam as vacinas de sarampo ${ }^{10}$. Nesse mesmo período, realizou-se a segunda campanha nacional de seguimento entre crianças de 6 meses a 4 anos de idade.

A principal pergunta desta pesquisa é "Podemos afirmar a erradicação do sarampo no Estado de Santa Catarina?”. Para respondê-la, enfocamos o período de cinco anos que precederam a eliminação da doença no Estado, período esse preconizado pelo programa estadual e nacional da erradicação de sarampo.

\section{Metodologia}

Este é um estudo ecológico descritivo e analítico, tendo como unidade de análise os municípios do Estado de Santa Catarina, no período de 1996 a 2000. O estudo tem como variável dependente a incidência de sarampo. As variáveis independentes são faixa etária ( $<1$ ano, 1-2 anos, 3-5 anos, 6-10 anos, 11-15 anos e 16 anos ou mais), cobertura vacinal $(<60 \%, 60-79 \%, 80$ $89 \%, 90-94 \%, 95 \%$ e mais), tamanho de município (< 50 mil, 50-100 mil, > 100 mil habitantes) e a circulação do vírus no ano anterior (se teve, no mínimo, um caso de sarampo confirmado no município no ano anterior). A interação das duas últimas variáveis também foi analisada com relação à incidência de sarampo. Ressaltamos que a cobertura vacinal de $95 \%$ ou mais e no mínimo $90 \%$ é considerada necessária para erradicação e controle do sarampo, respectivamente 11 . As coberturas menores de 
$80 \%$ são consideradas baixas, e as menores de $60 \%$, muito baixas.

Dados secundários foram colhidos na Diretoria de Vigilância Epidemiológica da Secretaria de Estado da Saúde (DVE/SES) e no Ministério da Saúde (Departamento de Informática e Informação do SUS). As informações colhidas incluem o número de casos de sarampo segundo as fichas de investigação epidemiológica, número de doses de vacina contra sarampo aplicadas nos menores de um ano e nas crianças de 1 a 2 anos de idade, por município, assim como a população nessas faixas etárias segundo o Instituto Brasileiro de Geografia e Estatística, para cada ano do período de 1996 a 2000.

O guia de vigilância epidemiológica determina que um caso suspeito de sarampo é todo paciente, independente da idade e da situação vacinal, que apresentar febre alta acima de $38 \circ \mathrm{C}$, exantema mácula-papular generalizado, acompanhado de um ou mais sintomas como: tosse, coriza e conjuntivite 2 . A notificação do caso suspeito deverá ser feita nas primeiras 24 horas após o atendimento. Além disso, o serviço de saúde local deveria realizar a investigação epidemiológica, na qual as informações clínicas e laboratoriais servirão de apoio para confirmação do caso 11 .

Um caso de sarampo passa a ser confirmado quando os resultados dos exames laboratoriais realizados forem positivos para sarampo, quando houver vínculo epidemiológico (caso suspeito num período máximo de 7-18 dias, que teve contato com um ou mais casos de sarampo confirmados pelo laboratório), e quando houver morte após a doença compatível 2. Para finalidade deste estudo, a definição do caso de sarampo foi operacionalizada através do diagnóstico final (campo DIAGNOSE no banco de dados da DVE/SES), incluindo casos confirmados pelo laboratório, pelo vínculo epidemiológico, pela compatibilidade clínica e pelo óbito por sarampo.

Análises estatísticas incluem a percentagem de municípios nas faixas de cobertura vacinal acima definidas em menores de 1 ano e entre 12 a 23 meses de idade, descritas anualmente durante o período de 1996 a 2000, número de casos de sarampo nos municípios por faixa etária, assim como a relação entre a incidência do sarampo e a cobertura vacinal, tamanho de município e a circulação do vírus no ano anterior. O programa Epi Info 6.04d foi utilizado para calcular risco relativo com intervalos de confiança de $95 \%$ e para estatística descritiva.

\section{Resultados}

A cobertura vacinal nos municípios foi maior no primeiro ano de vida em quase todo o tempo analisado (Figura 1a), porém a homogeneidade não foi registrada para todos os municípios do Estado de Santa Catarina. A cobertura vacinal, no segundo ano de vida (Figura 1b), foi baixa em muitos municípios durante todo período analisado. Apesar das melhores coberturas após a epidemia de 1997, cerca de metade dos municípios apresentaram coberturas inferiores a $90 \%$, o patamar considerado mínimo para controle da doença.

Aproximadamente $80 \%$ dos casos de sarampo no período de 1996-2000 ocorreram entre escolares e jovens adultos (Figura 1c). Os préescolares (até 5 anos de idade) contribuíram com menos de $15 \%$ de casos no ano epidêmico, porém mais que dobraram sua participação no total de casos quando esse diminuiu consideravelmente em 1999. Para cada ano, a faixa etária vacinada contra sarampo (1-2 anos) no mesmo ano teve pouca contribuição no total de casos, de ordem de $5 \%$. Nessa faixa etária, a maioria dos casos ocorreu em crianças maiores de um ano.

A relação entre coberturas de vacina contra sarampo no 1o e no 2 o ano de vida versus a incidência do sarampo não segue nenhum padrão simples. Em 1996, a maior incidência foi registrada nos municípios onde ambas coberturas ficaram na faixa de $80 \%$ a $89 \%$ (Figura 2). Porém, menores surtos ocorreram nos municípios com cobertura de $95 \%$ ou mais no 1o ano, com maior concentração naqueles com baixa cobertura no 2o ano de vida. Em 1997, baixa cobertura $(<60 \%)$ no 2 o ano de vida foi associada com alta incidência, particularmente nos municípios onde a cobertura no 1o ano também foi baixa (Figura 2). Por outro lado, nesse ano epidêmico, a terceira incidência mais alta foi observada nos municípios com ambas coberturas de 95\% ou mais. Em 1998, a maior incidência foi encontrada nos municípios com cobertura vacinal no 10 ano de vida menor de $60 \%$ e a cobertura de $90 \%$ a $94 \%$ no 2 o ano de vida, mas nem os municípios com cobertura ideal no 1o ano evitaram pequenos surtos (Figura 2). Em 1999, a incidência de sarampo em qualquer categoria dos municípios agrupados pela cobertura vacinal não ultrapassou 1/100 mil habitantes, atingindo principalmente alguns municípios com coberturas médias e altas no 1 o ano de vida e a cobertura de $95 \%$ ou mais no 2 o ano de vida.

Os efeitos do tamanho da população e da presença do sarampo no ano anterior no mu- 


\section{Figura 1}

Distribuição dos municípios do Estado de Santa Catarina, Brasil, segundo cobertura vacinal contra sarampo

em menores de um ano (a) e no $2^{\circ}$ ano (b), e distribuição dos casos de sarampo por faixa etária (c).

Figura 1a

Cobertura vacinal em menores de um ano

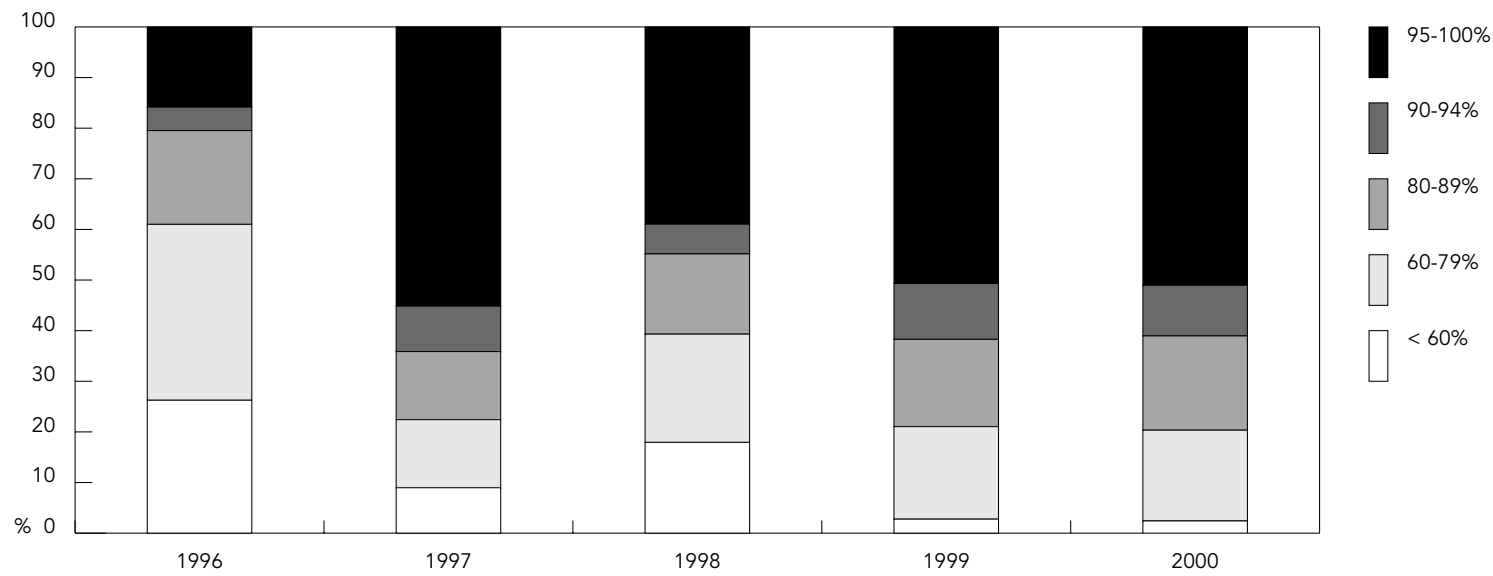

Figura $1 b$

Cobertura vacinal no 2 o ano de vida.

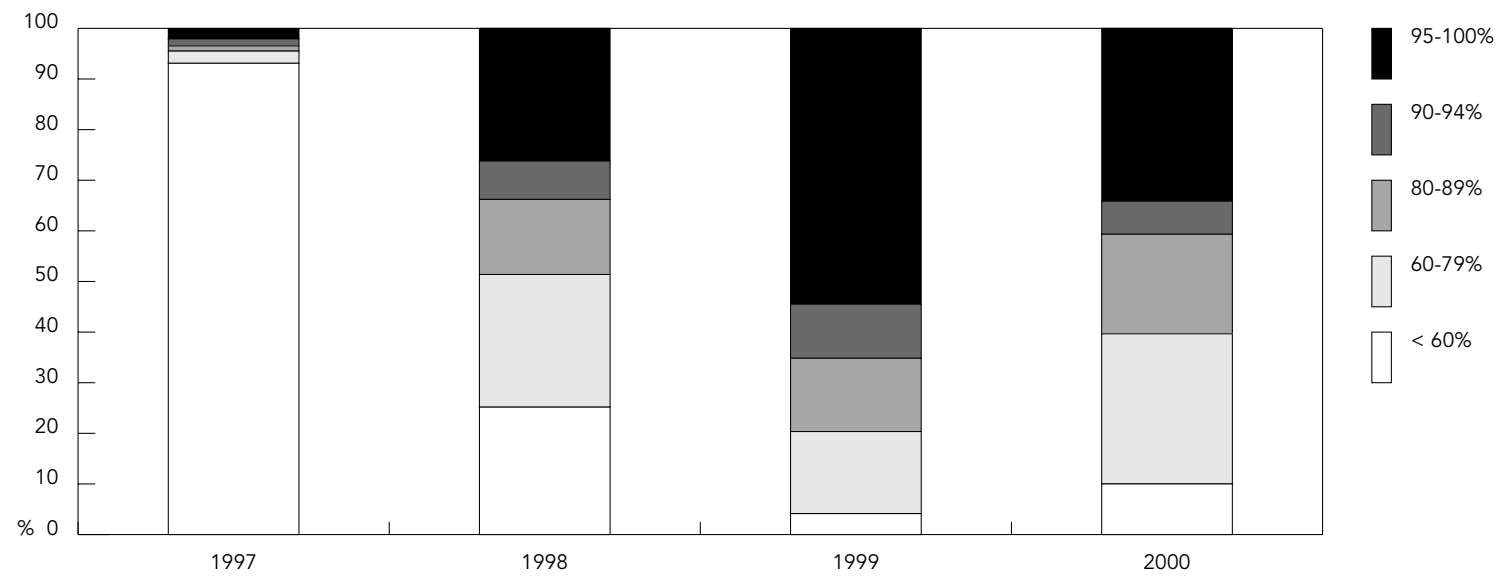




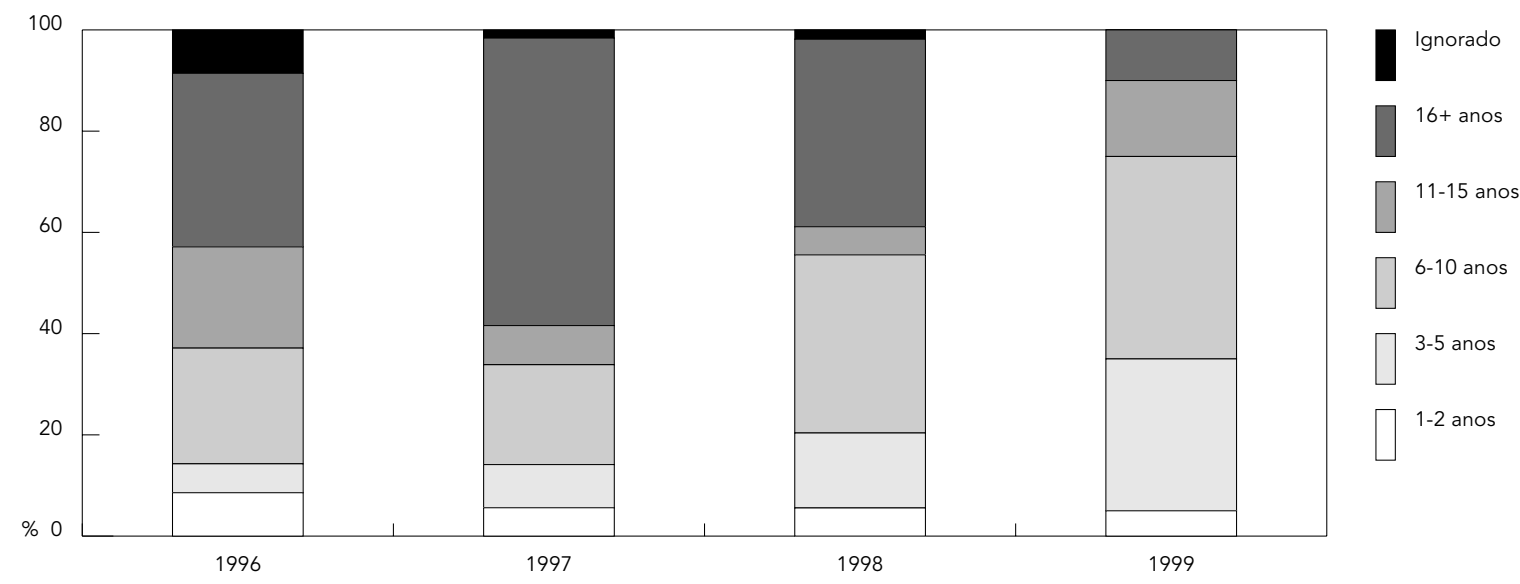

nicípio foram analisados separadamente e em conjunto. Os municípios com população acima de 100 mil habitantes tinham um risco maior de sarampo comparado com os municípios com menos de 50 mil habitantes; o risco relativo foi estatisticamente significativo em 1996, 1997 e 1999 (Tabela 1). Os municípios de médio porte não mostraram nenhum risco relativo significativo nessa comparação.

A circulação do vírus do sarampo no município no ano anterior aumentou o risco relativo de sarampo em todos os anos analisados, mas foi estatisticamente significativo em 1997 e 1999 (Tabela 2).

A análise da interação do tamanho de município e da circulação do vírus usou como referência os municípios de menor risco de sarampo (sem circulação do vírus no ano anterior e com menor densidade populacional). A análise mostrou que a maioria dos efeitos estatisticamente significativos se concentra no ano de 1997 (Tabela 3). Nesse ano, o risco de sarampo foi quase três vezes maior nos municípios acima de 50 mil habitantes com circulação do vírus no ano anterior comparado com os municípios com menos de 50 mil habitantes sem a circulação do vírus no ano anterior (Tabela 3). Porém, ainda nesse ano, o risco de sarampo foi quase quádruplo nas cidades acima de 100 mil habitantes, mesmo sem a presença do vírus no ano anterior. Na área sem a circulação do vírus no ano anterior, também foi observada redução de risco de sarampo em municípios de médio porte comparados com os menores de 50 mil habitantes em 1997. Um ano após a epidemia, nenhuma interação entre o tamanho populacional do município e a circulação do vírus foi estatisticamente significativa. A mesma situação se repetiu em 1999 nos municípios sem circulação do vírus no ano anterior, mas os municípios onde o sarampo foi registrado no ano anterior mostraram grande aumento de risco relativo (Tabela 3 ). O risco relativo foi estatisticamente significativo nos municípios com menos de 50 mil e com mais de 100 mil habitantes que registraram casos de sarampo no ano anterior comparado com municípios com menos de 50 mil sem sarampo no ano anterior.

A letalidade entre os casos confirmados de sarampo foi de $0,21 \%$.

\section{Discussão}

Antes de comentar os achados principais, é preciso mencionar algumas limitações do trabalho para que os resultados sejam avaliados com cautela. Número de casos de sarampo e a cobertura vacinal são dados secundários sem validação independente, provenientes da administração da saúde e passíveis a viés de informação. Por exemplo, a sensibilidade da vigilância epidemiológica é tipicamente maior no ano epidêmico e menor nos outros anos, além de variar entre os municípios. Outra limitação é oriunda do delineamento de um estudo ecológico que não permite interpretações diretas 


\section{Figura 2}

Incidência de sarampo nos subconjuntos de municípios formados pelas categorias de cobertura vacinal contra sarampo no Estado de Santa Catarina, Brasil.

\section{Figura 2a}

Ano 1996

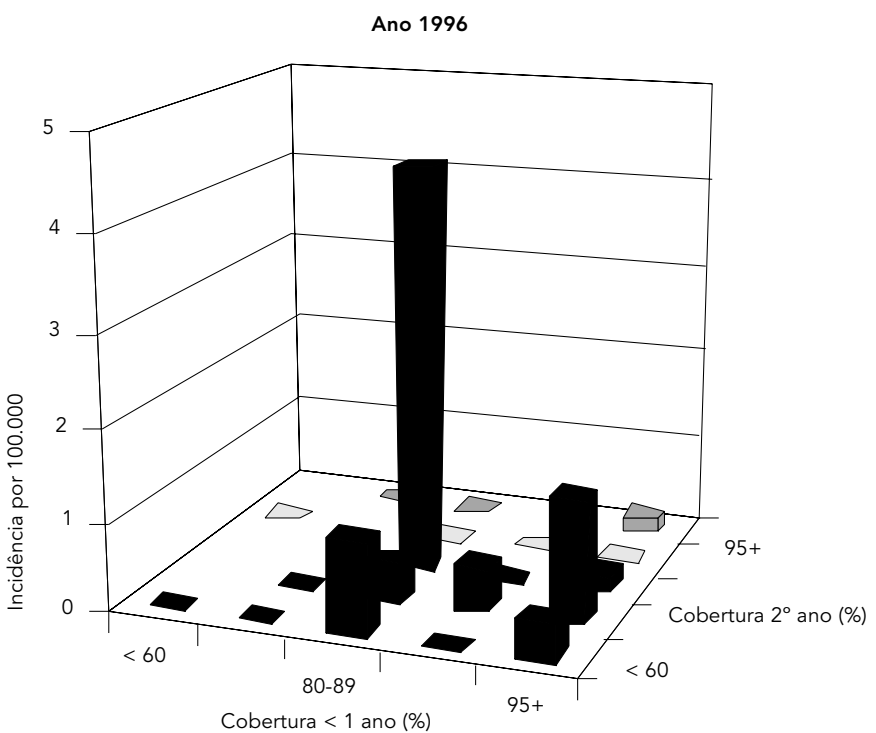

Figura $2 b$

Ano 1997

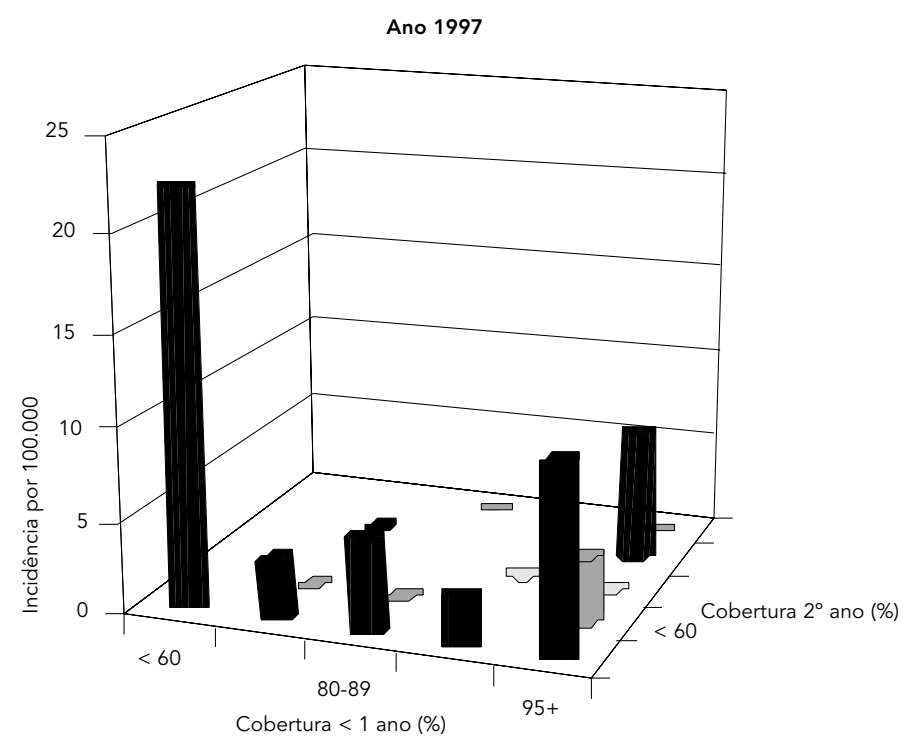

dos resultados no nível individual. A abordagem descritiva se limita às análises univariadas, não ajustando por diversos fatores de risco e suas interações nem por estrutura espacial de dados (proximidade de municípios com casos de sarampo), o que seria possível numa abordagem analítica mais complexa. O impacto da circulação do vírus de sarampo no ano anterior foi analisado usando um simples indicador de ocorrência em vez de freqüência. Finalmente, muitos outros fatores de risco, tais como a alteração da susceptibilidade da população em função da epidemia, não foram analisados por falta de dados.

Apesar das limitações, o estudo mostrou alguns resultados importantes. A cobertura da vacina contra sarampo foi inadequada tanto para erradicação quanto para controle da doença no Estado de Santa Catarina no período de 1996-2000. A manutenção dos níveis da cobertura de no mínimo $90 \%$ em todos os municípios foi o principal problema observado. Outros estudos mostraram problemas semelhantes no Estado de São Paulo 12,13, em Salvador, na Bahia 14, em Minas Gerais 15 e na Europa Ocidental 16 . Somente $56 \%$ dos municípios brasileiros têm cobertura acima de $95 \%$. 0 inquérito populacional de Moraes et al. 13 revelou que aproximadamente $86 \%$ das crianças foram vacinadas no primeiro ano de vida, e $83 \%$ receberam a primeira e a segunda dose, e que $17 \%$ das crianças estavam com imunização incompleta, ou seja, receberam apenas uma das doses de vacina ou não receberam nenhuma delas. Acúmulo de susceptíveis é ainda maior quando se acrescentam as gerações nascidas nas épocas de menor cobertura, concentrando-se entre adolescentes e jovens adultos. Isso explica porque a maioria dos casos de sarampo no ano epidêmico de 1997 foi nessa faixa etária, tanto no Estado de São Paulo 17,18 quanto em Santa Catarina (Figura 1c) e em outras regiões brasileiras 19. Ressaltamos ainda que a faixa etária vacinada contra sarampo (1-2 anos) em Santa Catarina teve pouca participação no total de casos, de aproximadamente $5 \%$, mesmo no ano epidêmico de 1997.

O impacto da cobertura vacinal no primeiro e segundo ano de vida na incidência não ocorreu de forma imediata, embora chame atenção a baixa proporção das crianças na idade pré-escolar entre casos de sarampo (Figura 1c). Apesar de o aumento da incidência geralmente ter sido registrado para os municípios onde ambas as coberturas foram baixas, no ano epidêmico de 1997, até alguns municípios com cobertura acima de $95 \%$ registraram uma elevada incidência de sarampo. No ano de 1998, 
melhorou a cobertura do segundo ano de vida com a adoção da vacina tríplice viral. Os resultados das coberturas de vacina anti-sarampo foram baixos em parte do estado antes, durante e após a epidemia de 1997. Houve uma tendência à diminuição das coberturas acima de 90\% após a epidemia, assim como um aumento nas coberturas inferiores a $90 \%$ no segundo ano de vida.

Apesar da diminuição da incidência nos anos após a epidemia, alguns focos de circulação do vírus do sarampo permaneceram no litoral do estado, em especial na grande Florianópolis, durante todo período analisado. Esse fato pode ser ligado ao achado que os municípios com população acima de 100 mil habitantes têm maior risco de sarampo comparado aos municípios com população inferior a $50 \mathrm{mil}$ habitantes. Um dos maiores fatores que contribuíram para o risco de sarampo foi a circulação do vírus no ano anterior, principalmente no ano epidêmico quando o risco foi quase três vezes maior nos municípios com população acima de 50 mil habitantes que registraram sarampo no ano anterior (Tabela 3). A magnitude

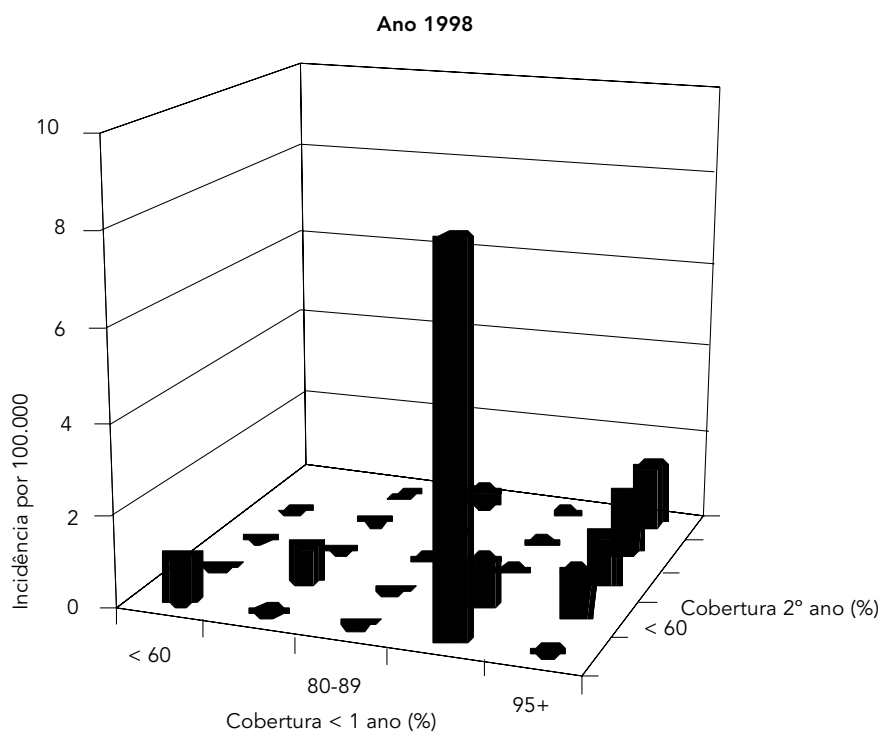

Cobertura $<1$ ano $(\%)$

Incidência do sarampo por 100 mil habitantes, risco relativo (RR) com relação ao tamanho de município e intervalo de confiança de $95 \%$ (IC95\%).

\begin{tabular}{|c|c|c|c|c|c|}
\hline $\begin{array}{l}\text { Tamanho de } \\
\text { município }\end{array}$ & Indicador & 1996 & 1997 & 1998 & 1999 \\
\hline \multirow[t]{3}{*}{$<50 \mathrm{mil}$} & Casos & 7 & 115 & 20 & 7 \\
\hline & População & 2.680 .633 & 2.578 .419 & 2.652 .860 & 2.678 .275 \\
\hline & Incidência* & 0,2611 & 4,4601 & 0,7539 & 0,2614 \\
\hline \multirow[t]{5}{*}{ 50-100 mil } & Casos & 1 & 27 & 10 & 1 \\
\hline & População & 703.203 & 667.359 & 689.856 & 602.981 \\
\hline & Incidência & 0,1422 & 4,0458 & 1,4496 & 0,1658 \\
\hline & $\mathrm{RR}$ & 0.54 & 0,91 & 1,68 & 0,63 \\
\hline & IC95\% & $0,07-4,43$ & $0,60-1,38$ & $0,79-3,59$ & $0,08-5,16$ \\
\hline \multirow[t]{5}{*}{$>100 \mathrm{mil}$} & Casos & 12 & 233 & 19 & 12 \\
\hline & População & 1.706 .009 & 1.625 .574 & 1.677 .163 & 1.808 .589 \\
\hline & Incidência & 0,7034 & 14,3334 & 1,1329 & 0,6635 \\
\hline & $\mathrm{RR}$ & 2.693 & 3,21 & 1,50 & 2,54 \\
\hline & IC95\% & $1,06-6,84$ & $2,47-4,02$ & $0,80-2,82$ & $1,00-6,45$ \\
\hline
\end{tabular}

* Categoria de referência. 


\section{Tabela 2}

Incidência do sarampo por 100 mil habitantes, risco relativo (RR) com relação à circulação do vírus no município no ano anterior e ao intervalo de confiança de $95 \%$ (IC95\%)

\begin{tabular}{llccc}
\hline $\begin{array}{l}\text { Circulação } \\
\text { do vírus }\end{array}$ & Indicador & 1997 & 1998 & 1999 \\
\hline Sim & Casos & 151 & 31 & 16 \\
& População & 1.246 .498 & 2.867 .110 & 1.761 .749 \\
& Incidência & 12,114 & 1,081 & 0,908 \\
& RR & 1,96 & 1,29 & 7,56 \\
& IC95\% & $1,59-2,41$ & $0,72-2,31$ & $2,53-22,60$ \\
& Casos & 224 & & 4 \\
& População & 3.624 .854 & 2.152 .769 & 3.328 .096 \\
& Incidência* & 6,180 & 0,836 & 0,120 \\
\hline
\end{tabular}

* Categoria de referência. fronteira de Ciudad Del Este e Foz de Iguaçu, com densidade populacional de aproximadamente 700 mil habitantes, a cobertura no período da epidemia era de $40 \%$ a $60 \%$. Os municípios de grande porte no leste do Estado de Santa Catarina apresentaram as maiores incidências antes, durante e após a epidemia de 1997, sendo possivelmente a porta de entrada do vírus no Estado de Santa Catarina durante o período analisado. Esses dados mostram a vulnerabilidade do Brasil à importação do vírus e a necessidade de ações conjuntas com outros países, principalmente os vizinhos.

Um estudo importante de comparação do perfil de anticorpos contra o sarampo ao longo prazo, desenvolvido em Taiwan após a epidemia de 1988-89 e visando à erradicação da doença até o ano de 2000, indicou a mudança no esquema de imunização 22 . O estudo revelou que o esquema vacinal de 9 meses para a primeira dose de vacina e um reforço aos 15 meses de idade com a tríplice viral garantem uma proteção contra sarampo entre 2 a 5 anos de $81-94 \%$ dos vacinados, assumindo o tempo médio de 4 anos em que a metade dos vacinados perdem os títulos de anticorpos do sarampo necessários para proteger-se da infecção. Se a primeira dose da vacina for aplicada aos 12 meses de idade, atingindo com homogeneidade a cobertura de $90-95 \%$, a segunda dose deverá ser aplicada aos 6 anos 22. Em nosso estudo, foram reveladas coberturas insuficientes com a primeira dose e principalmente com a segunda dose. A exemplo do estudo realizado em Taiwan, a modificação no esquema vacinal garante maior proteção também aos adolescentes. A modificação foi parcialmente acatada pelo PNI a partir de janeiro de 2003, mudando o esquema vacinal de rotina para aplicação da vacina triviral aos 12 meses de idade e suspensão da vacina anti-sarampo monovalente aos nove meses de idade 7 . Será de grande importância acrescentar a segunda dose de vacina no primeiro ano da escola, apoiando-se às facilidades logísticas desse tipo de vacinação.

Para garantia da erradicação do sarampo no Estado de Santa Catarina, é preciso acrescentar novas medidas para alcançar maior homogeneidade das altas coberturas. Apesar da ausência de casos autóctones de sarampo por mais de quatro anos no estado, a eliminação temporária e não a erradicação da doença seria a descrição pertinente dessa conquista importante na saúde pública. 
Incidência do sarampo por 100 mil habitantes, risco relativo (RR) com relação ao tamanho de município, à circulação do vírus no município no ano anterior e ao intervalo de confiança de 95\% (IC95\%).

\begin{tabular}{|c|c|c|c|c|c|}
\hline $\begin{array}{l}\text { Circulação } \\
\text { do vírus }\end{array}$ & $\begin{array}{l}\text { Tamanho de } \\
\text { município }\end{array}$ & Indicador & 1997 & 1998 & 1999 \\
\hline \multirow[t]{13}{*}{ Não } & $<50$ mil & Casos & 106 & 14 & 4 \\
\hline & & População & 2.459 .012 & 1.887 .805 & 2.455 .779 \\
\hline & & Incidência* & 4,3107 & 0,7416 & 0,1629 \\
\hline & $50-100 \mathrm{mil}$ & Casos & 8 & 4 & 0 \\
\hline & & População & 519.625 & 264.964 & 320.707 \\
\hline & & Incidência & 1,5396 & 1,5096 & 0,0000 \\
\hline & & $\mathrm{RR}$ & 0,36 & 2,04 & $\star \star \star$ \\
\hline & & IC95\% & $0,17-0,73$ & $0,67-6,18$ & $\star \star \star$ \\
\hline & $>100 \mathrm{mil}$ & Casos & 110 & $\star \star$ & 0 \\
\hline & & População & 646.217 & $\star \star$ & 551.610 \\
\hline & & Incidência & 17,0221 & $\star \star$ & 0,0000 \\
\hline & & $\mathrm{RR}$ & 3,95 & $\star \star *$ & $\star \star \star$ \\
\hline & & IC95\% & $3,02-5,16$ & $\star \star$ & $\star \star \star$ \\
\hline \multirow[t]{16}{*}{ Sim } & $<50 \mathrm{mil}$ & & & & \\
\hline & & Casos & 9 & 6 & 3 \\
\hline & & População & 119.407 & 765.055 & 222.496 \\
\hline & & Incidência & 7,5372 & 0,7842 & 1,3483 \\
\hline & & $\mathrm{RR}$ & 1,75 & 1,06 & 8,28 \\
\hline & & IC95\% & $0,89-3,45$ & $0,41-2,75$ & $1,85-36,99$ \\
\hline & $50-100 \mathrm{mil}$ & Casos & 19 & 6 & 1 \\
\hline & & População & 147.734 & 424.892 & 282.274 \\
\hline & & Incidência & 12,8609 & 1,4121 & 0,3543 \\
\hline & & $\mathrm{RR}$ & 2,98 & 1,90 & 2,17 \\
\hline & & IC95\% & $1,83-4,86$ & $0,73-4,96$ & $0,24-19,46$ \\
\hline & $>100 \mathrm{mil}$ & Casos & 123 & 19 & 12 \\
\hline & & População & 979.357 & 1.677 .163 & 1.256 .979 \\
\hline & & Incidência & 12,5593 & 1,1329 & 0,9547 \\
\hline & & RR & 2,91 & 1,53 & 5,77 \\
\hline & & IC95\% & $2,25-3,78$ & $0,77-3,05$ & $1,86-17,89$ \\
\hline
\end{tabular}

* Categoria de referência.

** Empiricamente não encontrado.

*** RR impossível de calcular, mas o teste exato de Fisher não foi significativo no nível 0,05.

\section{Resumo}

Este estudo ecológico, baseado nos dados secundários da vigilância epidemiológica e usando município como unidade de análise, mostrou que as coberturas da vacina contra sarampo foram menores de níveis necessários para erradicação (95\%) e controle (90\%) em grande parte do Estado de Santa Catarina, Brasil, antes e durante a epidemia de 1997, principalmente da segunda dose da vacina, prevista para 15 meses de idade dentro da vacina triviral. Houve melhora nos anos seguintes, mas continuou faltando a homogeneidade da cobertura. Baixas coberturas vacinais foram associadas com maior incidência de sarampo, mas, no ano epidêmico de 1997, surtos menores de sarampo ocorreram até em alguns municípios com coberturas acima de 95\% no primeiro ano de vida, com maior concentração naqueles com baixa cobertura da vacina triviral. Cerca de $80 \%$ dos casos de sarampo no período de 1996-2000 ocorreram entre escolares e jovens adultos. A circulação do vírus do sarampo no ano anterior e a densidade populacional aumentaram o risco de sarampo. Dois casos importados em 2004 ilustram bem porque ainda não podemos falar de erradicação $e$ sim de eliminação do sarampo no Estado.

Sarampo; Incidência; Vacina contra Sarampo 


\section{Colaboradores}

M. C. S. S. Faversani organizou os dados, escreveu a primeira versão do texto e contribuiu para sucessivas modificações. E. Kupek contribuiu com apuração de dados, análise estatística e interpretação dos resultados. M. H. B. Westrupp participou no planejamento de pesquisa, interpretação dos resultados e edição do texto.

\section{Agradecimentos}

Os autores agradecem a Ilze Lisiane V. Vieira, Alda Maric Rodolfo da Silva, Udson Piazza e Lúcia Prim da Diretoria da Vigilância Epidemiológica do Estado de Santa Catarina por ter disponibilizado os dados e por seus valiosos comentários.

\section{Referências}

1. Farhat C. Preceitos básicos da imunização. In: Farhat C, organizador. Fundamentos e práticas das imunizações em clínica médica e pediatria. Rio de Janeiro: Atheneu; 1989. p. 3-7.

2. Ministério da Saúde. Guia de vigilância epidemiológica. Brasília: Centro Nacional de Epidemiologia, Fundação Nacional de Saúde; 1998.

3. Quadros CA, Olive JM, Hersh BS, Strassburg MA, Henderson DA, Brandling-Bennett D, et al. Measles elimination in Americas: evolving strategies. JAMA 1996; 275:224-9.

4. Diretoria de Vigilância Epidemiológica de Santa Catarina. Boletim do programa de controle e eliminação do sarampo em Santa Catarina. Florianópolis: Diretoria de Vigilância Epidemiológica de Santa Catarina; 2002.

5. Diretoria de Vigilância Epidemiológica de Santa Catarina. Relatório do programa de controle e eliminação do sarampo em Santa Catarina. Florianópolis: Diretoria de Vigilância Epidemiológica de Santa Catarina; 1999.

6. Organización Panamericana de la Salud. Los países del cono sur: hacia la erradicación del sarampión. Boletín Informativo PAI 2000; 22:4-5.

7. Ministério da Saúde. Guia de vigilância epidemiológica. Brasília: Fundação Nacional da Saúde; 2002.

8. Diretoria de Vigilância Epidemiológica de Santa Catarina. Relatório do programa de controle e eliminação do sarampo em Santa Catarina. Florianópolis: Diretoria de Vigilância Epidemiológica de Santa Catarina; 1996.

9. Ministério da Saúde. Relatório da reunião nacional de avaliação do plano de erradicação do sarampo e plano de controle da rubéola. Rio de Janeiro: Fundação Nacional de Saúde; 1999.

10. Ministério da Saúde. Sarampo. Boletim Epidemiológico 1999; III (Edição Especial):22-3.

11. Ministério da Saúde. Guia de vigilância para a erradicação do sarampo e controle da rubéola. Brasília: Fundação Nacional de Saúde; 2000.

12. Camargo MC, Moraes JC, Souza VA, Matos MR, Panutti CS. Predictors related to the occurrence of a measles epidemic in the city of São Paulo in 1997. Rev Panam Salud Publica 2000; 7:359-65.
13. Moraes JC, Ribeiro MCSA, Simões O, Castro PC, Barata RB. Inquérito de cobertura vacinal no primeiro ano de vida para a coorte de nascidos entre setembro de 1997 e agosto de 1998 residentes no Estado de São Paulo, 2000. V Congresso Brasileiro de Epidemiologia. Curitiba: ABRASCO; 2002. p. 14

14. Andrade MAS. Fatores de risco da soronegatividade para anticorpos Igg contra o sarampo [Dissertação de Mestrado]. Salvador: Universidade Federal da Bahia; 1999.

15. Oliveira MTC, Caiaffa WT. Resurgimiento de la epidemia de sarampión: situación de Minas Gerais, Brasil. Rev Panam Salud Publica 1998; 4:252.

16. Melker H, Pebody RG, Edmunds WJ, Levy-Bruhl D, Valle M, Rota M, et al. The seroepidemiology of measles in Western Europe. Epidemiol Infect 2001; 126:249-59.

17. Organización Panamericana de la Salud. Paraguay y Brasil tratan estrategias conjuntas para la erradición del sarampión. Boletín Informativo PAI 1998; 2:1-8.

18. Quadros CA. Actividades de la eliminación del sarampión en las Américas. Rev Esp Salud Pública 1999; 73:589-96.

19. Hersh BS, Tambini G, Nogueira AC, Carrasco P, Quadros CA. Review of regional measles surveillance data in the Americas, 1996-99. Lancet 2000; 355:1943-8.

20. Siqueira MM, Castro-Silva R, Cruz C. Genomic characterization of wild-type measels virus that circulated in different states of Brazil during the 1997 measles epidemic. J Med Virol 2001; 3:299-304.

21. Barrero PR, Zandomeni RO, Mistchenko AS. Measles virus circulation in Argentina: 1991-1996. Arch Virol 2001; 146:815-23.

22. Lee MS, Nokes DJ. Predicting and comparing long-term measles antibody profiles of different immunization policies. Bull World Health Organ $2001 ; 79: 615-24$

Recebido em 09/Mai/2003

Versão final reapresentada em 20/Ago/2004

Aprovado em 20/Set/2004 